\title{
Magnetic Properties of Iron Oxides in the Human Globus pallidus
}

\section{Martin Kopáni ${ }^{1 *}$, Jana Hlinková1, Hermann Ehrlich², Dušan Valigura ${ }^{3}$ and Roman Boča ${ }^{3}$}

${ }^{1}$ Institute of Medical Physics, Biophysics, Informatics and Telemedicine, Comenius University, Bratislava, Slovakia

2Institute of Experimental Physics, TU Bergakademie Freiberg, Freiberg, Germany

${ }^{3}$ Department of Chemistry, University of SS Cyril and Methodius, Trnava, Slovakia

\begin{abstract}
Several types of iron oxides can be found in the various parts of the human brain. These can be highlighted in the light microscopy and using scanning or transmission mode of the electron microscopy. Some of them are non-magnetic, some, on the contrary, display magnetic response. It is not clear which kind of magnetic particles are accumulated in the human brain as inorganic deposits. Light microscopy, electron microscopy and sensitive Superconducting Quantum Interference Device (SQUID magnetometer) were used in order to detect iron deposits and their magnetic response in the samples extracted from the Globus pallidus of the human brain. Electron microscopy reveals a presence of the single crystals of hematite $\left(\alpha-\mathrm{Fe}_{2} \mathrm{O}_{3}\right)$ of the size up to $1000 \mathrm{~nm}$ in the samples extracted from G. pallidus because of the diffractograms characteristic for the hexagonal unit cell; this mineral offers basically a diamagnetic response. The temperature dependence of the magnetic susceptibility allows a classification of the samples into three groups: mostly diamagnetic I, prevailing paramagnetic III, and an intermediate class II. The bulk samples exhibit a long-range magnetic ordering with magnetic hysteresis evidenced not only at low temperature but also at the room temperature. The recorded magnetic functions refer either to the presence of magnetite $\left(\mathrm{Fe}_{3} \mathrm{O}_{4}\right)$, or maghemite $\left(\mathrm{y}-\mathrm{Fe}_{2} \mathrm{O}_{3}\right)$. Iron oxides and oxidohydroxides found as inorganic deposits in the human brain can result from interaction between iron and microenvironment in the form of polysaccharides of glycoconjugates. They display magnetoactivity characteristic for magnetite and/or maghemite.
\end{abstract}

Keywords: Iron; Brain; Globus pallidus; Superconducting Quantum Interference Device (SQUID magnetometry); Polysaccharides

Abbreviations: Ft-H: Heavy Chain of Ferritin; Ft-L: Light Chain of Ferritin; RSO Mode: Reciprocating Sample Option Mode; SEM: Scanning Electron Microscopy; SQUID Magnetometry: Superconducting Quantum Interference Device Magnetometry; TEM: Transmission Electron Microscopy; ZFCM/FCM: Zero Field Cooled Magnetization/ Field Cooled Magnetization

\section{Introduction}

Iron, as the most abundant transition metal in the human brain, occurs with uneven distribution. Highest concentration of iron can be observed in areas associated with motor function (Globus pallidus, putamen, Substantia nigra) than in other areas of the human brain $[1,2]$. Therefore, the actual role of iron accumulation in brain pathobiology is an active area of investigation nowadays [3]. It is evident that amount of iron in brain gradually grows with age. Accumulation of iron in basal ganglia is probably associated with neuronal death leading to Alzheimer disease, Parkinson disease, epilepsy, Huntington disease, dementia with Lewy bodies, and multiple sclerosis [4-8]. It was reported that iron participates in redox reactions, and catalyzes the formation of reactive oxygen species responsible for oxidative stress and damaging processes [9-11].

Iron in the human brain can be found mostly in the form of ferritin, hemosiderin (a product of ferritin breakdown) and other biomineralized oxidohydroxides and oxides such as hematite, magnetite, and maghemite $[12,13]$. Ferritin, as an iron storage nonheme-protein with diameter up to $12 \mathrm{~nm}$, consist of inorganic core $(6 \mathrm{~nm})$ formed of ferrihydrite and minor portion of magnetite and hematite that is enclosed by two types of polypeptides [14]. The role of the heavy (Ft-H) form polypeptide coat of ferritin is to catalyze $\mathrm{Fe}(\mathrm{II})$ to $\mathrm{Fe}$ (III) ions whereas the light (Ft-L) polypeptide coat promotes the formation of ferritin iron core $[15,16]$. The amount of Ft-H and Ft-L polypeptide coats changes during ageing and the magnetic properties of ferritin can also alter.
In terms of the response to the magnetic field, three different classes of species were identified in the brain: The diamagnetic matrix (organic tissues, myelin, oxyhemoglobin), paramagnetic deoxyhemoglobin, paramagnetic/superparamagnetic ferritin and hemosiderin along with ferrimagnetic magnetite or maghemite [17-19].

In our previous work we studied iron distribution and magnetic properties in the human spleen and in G. pallidus of the human brain and their relationships to glycoconjugates $[20,21]$. The aim of this study is to investigate the magnetic properties of these iron deposits by the Superconducting Quantum Interference Device (SQUID) and asset the effect of glycoconjugates microenvironment.

\section{Materials and Methods}

\section{Samples}

Postmortem brain tissue sections from Globus pallidus externus were routinely obtained during the autopsy to prepare tissue sections for the pathology diagnosis at Department of pathology, Comenius University, Bratislava. Tissues were taken from individuals without clinical findings of any motor abnormalities, iron metabolism, movements involving limbs, face, and tongues (Table 1). All procedures were conducted in accordance with the Declaration of Helsinki.

*Corresponding author: Martin Kopáni, Faculty of Medicine, Institute of Medical Physics, Biophysics, Informatics and Telemedicine, Comenius University, Bratislava, Slovakia, Tel: 00421259357530; E-mail: martin.kopani@fmed.uniba.sk

Received February 26, 2017; Accepted March 15, 2017; Published March 22 2017

Citation: Kopáni M, Hlinková J, Ehrlich H, Valigura D, Boča R (2017) Magnetic Properties of Iron Oxides in the Human Globus pallidus. J Bioanal Biomed 9: 080090. doi:10.4172/1948-593X.1000158

Copyright: @ 92017 Kopáni M, et al. This is an open-access article distributed under the terms of the Creative Commons Attribution License, which permits unrestricted use, distribution, and reproduction in any medium, provided the original author and source are credited. 
During the sample preparation, special attention was paid to avoid manipulations with magnetizable instruments. Fresh, soft tissues were dried in vacuum and the resulting samples were obtained in a form of powder that was used for magnetic measurements.

\section{Light microscopy}

The samples of $2 \times 2 \mathrm{~cm}$ size were fixed in $10 \%$ formaldehyde for $24 \mathrm{~h}$ and embedded in paraffin blocks, cut by microtome to $5 \mu \mathrm{m}$ thin sections and mounted on gelatin-coated slides. Sections were stained for general morphological purposes by Perls' method (Table 2). Tissue sections were then covered by cover glass. Measurements by inductively coupled plasma mass spectrometry before and after the fixation process with formaldehyde solution showed that no leakage of tissue iron into the buffer solution had occurred [22].

Immunohistochemistry of human samples was performed on 10 $\mu \mathrm{m}$ paraffin embedded sections. Tissue sections were pretreated for 20 min with Antigen unmasking solution (Vector Laboratories, California) and for $1 \mathrm{~min}$ with $100 \%$ formic acid (Sigma-Aldrich, Germany). Sections were blocked with $1 \%$ BSA (Sigma-Aldrich, Germany) and incubated overnight with anti-ferritin light chain antibody ab110017 (Abcam, Cambridge, UK) at $4^{\circ} \mathrm{C}$ in the blocking solution. All sections were incubated with a biotinylated secondary antibody at room temperature for $1 \mathrm{~h}$, and then treated with avidin-biotin peroxidasecomplex for $60 \mathrm{~min}$. The staining was visualized using Vector VIP kit (Vector Laboratories, California, USA) (Table 2). Tissue sections were then covered by cover glass and the samples were examined under the light microscope Eclipse E50i (Nikon, Japan).

\section{Transmission electron microscopy (TEM) and electron diffraction}

The samples investigated in light microscopy were removed from slide, prepared in powder form and cut by ultramicrotome for transmission electron microscopy investigation. Sample were fixed in solution of glutar (di) aldehyde (SERVA, Heidelberg, Germany) for $2 \mathrm{~h}$ and buffered by phosphate ( $\mathrm{pH}$ 7.2-7.4). The samples were then washed by phosphate buffer and post fixed by $\mathrm{OsO}_{4}$ for $1 \mathrm{~h}$ in 0.0393 mol dm ${ }^{-3}$ solution buffered by phosphate, $\mathrm{pH}$ 7.2-7.4. After dehydration the tissue by alcohol, samples were embedded into Durcupan ACM (Fluka AG, Busch, Switzerland) as recommended by the manufacturer

\begin{tabular}{|c|c|c|c|c|}
\hline $\begin{array}{c}\text { Sample } \\
\text { classification }\end{array}$ & $\begin{array}{c}\text { Age at } \\
\text { decease }\end{array}$ & Sex $^{\mathrm{a}}$ & Cause of death & $\begin{array}{c}\text { Post-mortem interval in } \\
\text { hours }\end{array}$ \\
\hline Ia & 69 & $\mathrm{~F}$ & heart failure & 10 \\
\hline $\mathrm{Ib}$ & 52 & $\mathrm{M}$ & gastritis & 11 \\
\hline $\mathrm{Ila}$ & 83 & $\mathrm{~F}$ & heart failure & 8 \\
\hline Ilb & 66 & $\mathrm{M}$ & nephritis & 9 \\
\hline IIla & 53 & $\mathrm{M}$ & cirrhosis & 7 \\
\hline IIIb & 73 & $\mathrm{M}$ & fat embolus & 8 \\
\hline
\end{tabular}

${ }^{\mathrm{a}} \mathrm{M}$ : Male; F: Female

Table 1: Characteristics of the samples extracted from the Globus pallidus.

\begin{tabular}{|c|c|}
\hline Procedure & Interpretation of staining reactions \\
\hline Perls' method & Fe(III) ions, blue color \\
\hline $\begin{array}{c}\text { Anti-Ferritin Light Chain antibody } \\
\text { (polyclonal) } \\
\text { Abcam ab110017 }\end{array}$ & $\begin{array}{l}\text { Synthetic peptide: C-GEYLFERLTLKHD, } \\
\text { corresponding to C terminal amino acids } \\
163-175 \text { of Human Ferritin Light Chain }\end{array}$ \\
\hline
\end{tabular}

Table 2: Immunohistochemical reagents used in this study. and cut by ultramicrotome (Reichert, Wien, Austria). The thickness of samples was $200 \mathrm{~nm}$. Noncontrasted ultrathin sections were mounted on nickel grids and investigated by transmission electron microscope JEOL 840B (Jeol, Japan) with acceleration voltage of $150 \mathrm{kV}$. In order to determine the iron oxide phase chemical analysis EDX KEVEX 32051200 (Kevex, Valencia, USA) was applied. For phase identification was used International Centre for Diffraction Data (ICDD).

\section{SQUID magnetometry}

The SQUID apparatus (Quantum Design, MPMS-XL7) was used for measurements of the magnetic moment of the specimen in the RSO (reciprocating sample option) mode of detection. Powderlike lyophilized samples were weighed $(10-30 \mathrm{mg})$ into gelatin-made sample holders. The centering was done at $B=0.1 \mathrm{~T}$ and $T=5 \mathrm{~K}$. For the susceptibility measurements at the applied field $B_{0}=0.1 \mathrm{~T}$, temperature varied between $2 \mathrm{~K}$ and $300 \mathrm{~K}$. Magnetization measurements were conducted at $T_{0}=2.0 \mathrm{~K}$ and $4.6 \mathrm{~K}$ at the applied field of up to $B=7.0$ $\mathrm{T}$. The measured signal was converted to the mass magnetization and/ or mass magnetic susceptibility which are presented in SI units $\left(\mathrm{J} \mathrm{T}^{-1}\right.$ $\left.\mathrm{kg}^{-1}=\mathrm{A} \mathrm{m}^{2} \mathrm{~kg}^{-1}\right)$. Actual magnetic data is presented: Diamagnetic signal of the organic tissue is subtracted neither for susceptibility nor for magnetization. The susceptibility was measured first (virgin sample), then magnetization and magnetic hysteresis loop, and finally when cooling in the zero field, the ZFCM/FCM experiments were carried out. As the recorded signal of the specimen is small, there is a hardware problem when passing from the paramagnetic to the diamagnetic response on heating: the system is frustrated in fitting to the equation of a perfect dipole and the regression fit is rather bad. This may cause some artificial discontinuities on the recorded data. For instance, the sample Ia possesses the measured magnetic moment $+9.4 \times 10^{-7}$ (cgs and emu) at $T=8.2 \mathrm{~K}$ and $-5.3 \times 10^{-7}$ at $T=8.5 \mathrm{~K}$.

\section{Results}

\section{Optical microscopy}

Sections immunoreacted with ferritin showed two various structures in sample Ia. The first structure was ferritin positive glial cells. Ferritin immunostaining was present mainly on microglia and perivascular leukocytes in the human Globus pallidus. It is widely accepted that ferritin represents excellent marker of microglial cells.

In Figure 1 we demonstrated that ferritin was present in different stages of microglial activation and senescence, anti-ferritin antibody recognized reactive microglia (Figure 1A), hypertrophic microglia (Figure 1B), and dystrophic microglia (Figure 1C). The antibody did not recognize neurons or other types of glial cells. The second structure was a population of round, non-sharp-edged deposits of regular shape. The size of these ones ranged from $10 \mu \mathrm{m}$ to $20 \mu \mathrm{m}$ (Figure 1D). These deposits corresponded to iron detected by Perls' staining. Ferritin distribution revealed an irregular pattern with distinctive foci.

Perls' reaction revealed a population of blue round deposits of $\mathrm{Fe}(\mathrm{III})$ in sample Ia (Figure 2). The size Fe(III) round deposits in diameter ranged from $10 \mu \mathrm{m}$ to $20 \mu \mathrm{m}$. Turnbull reaction for Fe(II) detection revealed very fine granular blue deposits located sporadically around glial cells (not shown).

\section{Electron microscopy}

Selective electron diffraction in TEM showed the presence of well crystalline material of various structure with lattice parameters $a=0.503$ $\mathrm{nm}, c=1.375 \mathrm{~nm}$ corresponding to hematite in sample Ia. Some particles 

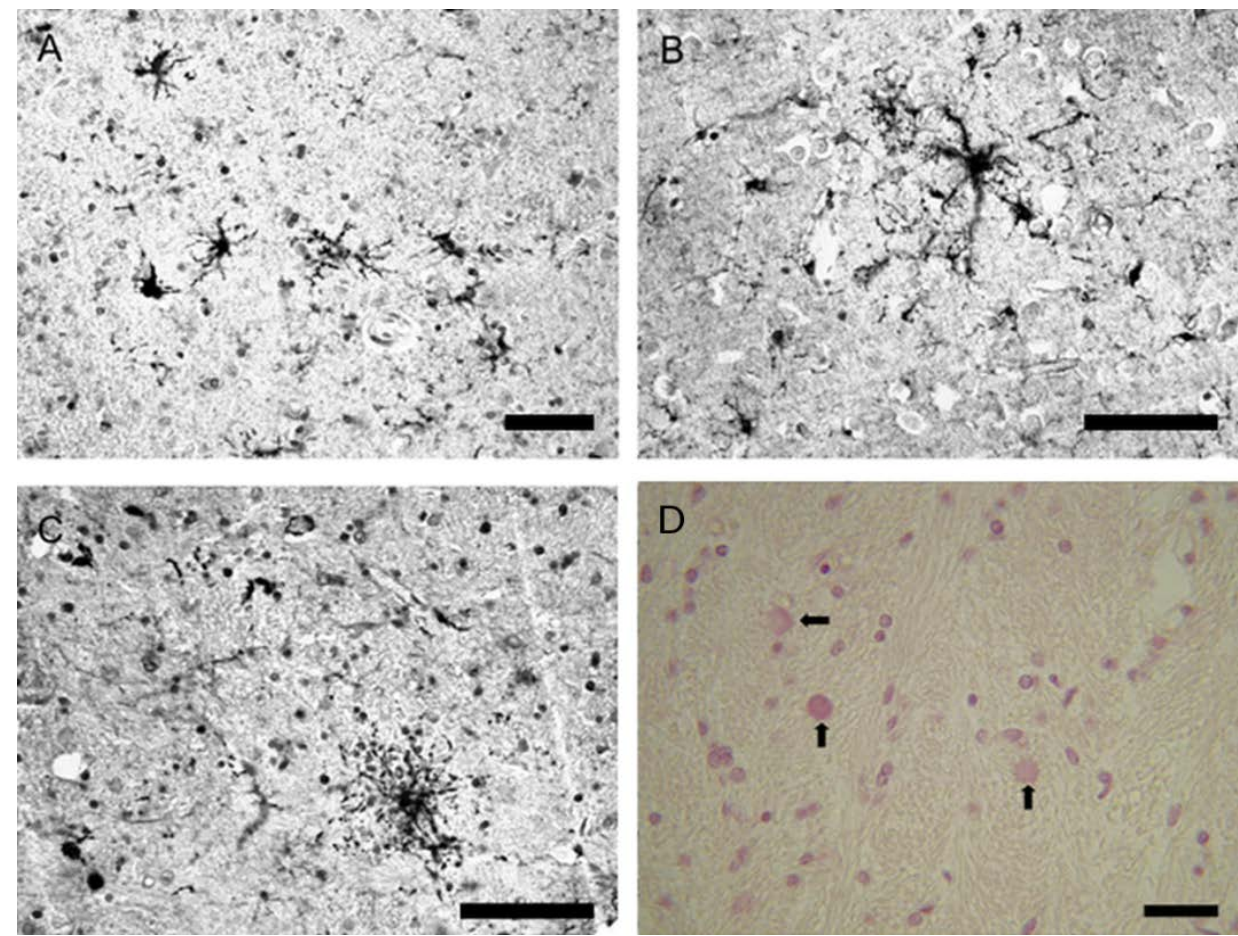

Figure 1: Human brain, Globus pallidus sample la. Ferritin shows ferritin labelled reactive microglia (A), hypertrophic microglia (B), dystrophic microglia (C), perivascular infiltrates of leukocytes and round, Perls' blue staining positive, non-sharp-edged deposits of regular shape (D). Scale bar=30 $\mu \mathrm{m}$.

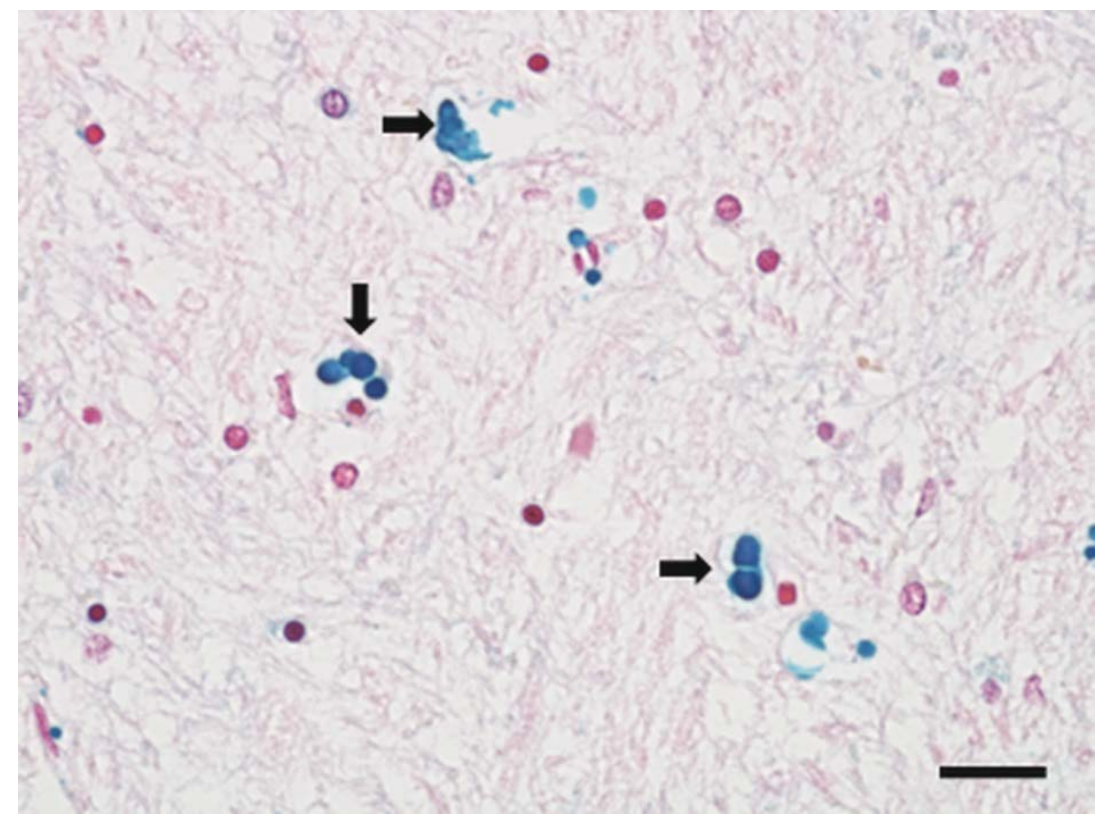

Figure 2: Human brain, Globus pallidus sample la. Blue dyed deposits correspond to the presence of $\mathrm{Fe}$ (III) ions (arrows) in the vicinity of glial cells. Light microscopy, scale bar $=30 \mu \mathrm{m}$.

were irregular, non-homogeneous, solid punctuate, sporadically exhibit hexagonal shape. The shape of smaller particles was more regular; the size varied around $2 \mu \mathrm{m}$. The shape of larger bumpy particles was more irregular (Figure 3). Sometimes the bumpy particles exhibit less ordered structure. The size of these particles was up to $6 \mu \mathrm{m}$. Small deposits of unknown origin can be seen on the surface of some particles.

\section{SQUID magnetometry}

Temperature dependence of the mass magnetic susceptibility $\chi$ (taken at $B=0.1 \mathrm{~T}$ ) is shown for three representative samples in Figure 4. The inverse susceptibility and the product function $\chi^{T}$ are plotted. The data reveals three groups of samples. Each class is represented at least by two examples; the data for the second member of each class were forwarded to Electronic supplementary material. 
Citation: Kopáni M, Hlinková J, Ehrlich H, Valigura D, Boča R (2017) Magnetic Properties of Iron Oxides in the Human Globus pallidus. J Bioanal Biomed 9: 080-090. doi:10.4172/1948-593X.1000158
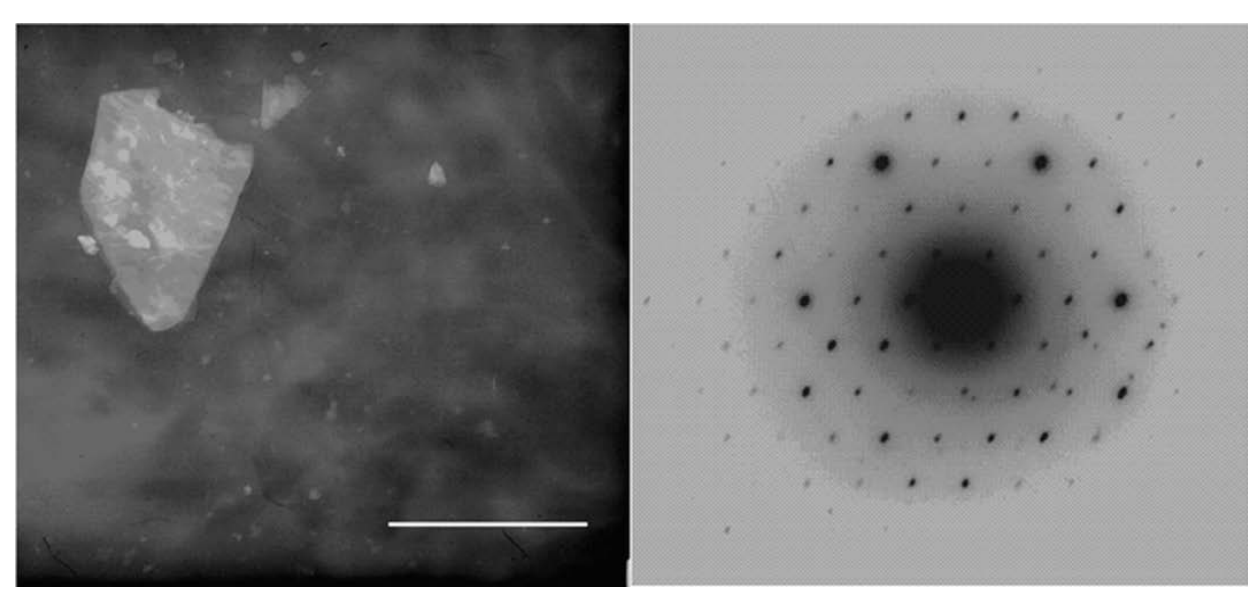

Figure 3: Human brain, Globus pallidus sample la. Irregular micrometer-sized particle (left) with diffraction pattern corresponding to hematite- $\alpha-\mathrm{Fe}_{2} \mathrm{O}_{3}$ (right). Transmission electron microscopy, scale bar- $1 \mu \mathrm{m}$.
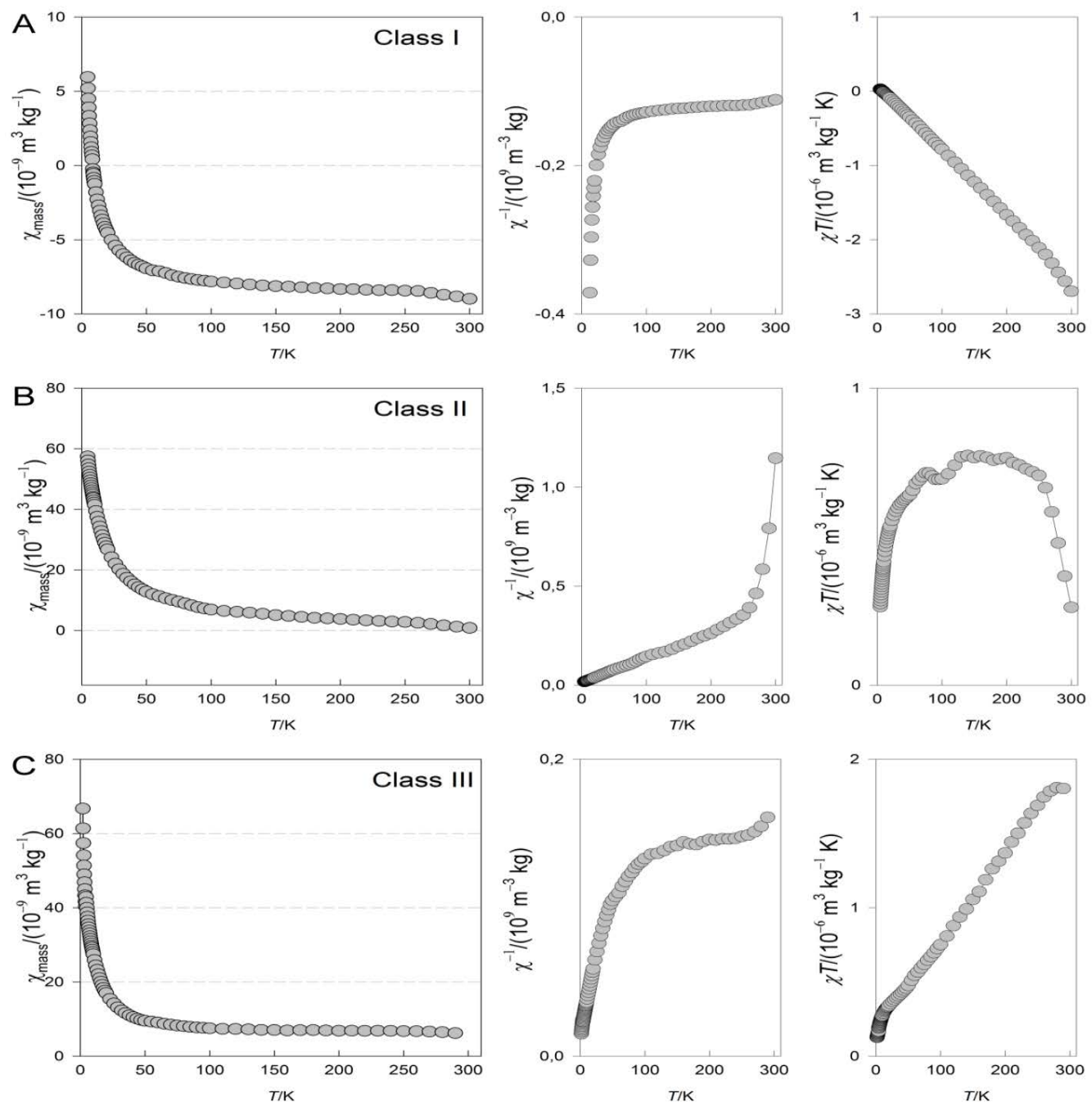

Figure 4: Classification of samples according to the magnetic susceptibility (virgin samples at $B=0.1 \mathrm{~T}$ ): A class I-sample la, B class II-sample Ila, C class III-sample IIla. 
Citation: Kopáni M, Hlinková J, Ehrlich H, Valigura D, Boča R (2017) Magnetic Properties of Iron Oxides in the Human Globus pallidus. J Bioanal Biomed 9: 080-090. doi:10.4172/1948-593X.1000158

Class I contains dominating diamagnetic species with an admixture of paramagnetic entities registered at low temperature. The product function $\chi T v s$. $T$ develops according to a straight line with a negative slope.

Class III, on the other hand, displays paramagnetism over the whole temperature range $(2-300 \mathrm{~K})$. The $\chi T$ vs. $T$ function is linear, but with a positive slope. The diamagnetic signal of the organic tissues is superimposed by much stronger paramagnetic (or ferromagnetic) signal of the admixture present in the sample.

Class II is intermediate between class I and III. The overall magnetoactivity corresponds to paramagnetism; the $\chi T$ vs. $T$ function displays a complex behavior. The susceptibility decays almost to the zero at the room temperature.

The $\chi T$ product function in the interval $\mathrm{T}=150-250 \mathrm{~K}$ has been fitted by a straight line $\chi T=C+\alpha T$ and the data are presented in Table 3 .

The ferro-/ferrimagnetic nanoparticles exposed to a strong magnetic field (5-7 T) could orient themselves along an easy axis so that the subsequent susceptibility measurements in the longitudinal field could reflect the ordered sample with prevailing paramagnetism. Notice, the RSO mode of the operation means that the sample oscillates with defined frequency $(4 \mathrm{~Hz})$ within the detection coil so that the corresponding force supports the ordering of nanoparticles.

\section{Magnetization data for class I}

The magnetization measurement conducted for the representative class I compound is shown in Figure 5. This is caused by the superposition of the Langevin function weighted by the amount of the paramagnetic (ferro/ferrimagnetic) fraction $w_{\mathrm{PF}}$ and the constant negative contribution from the diamagnetic tissue $\chi_{\text {dia }}$. The magnetization curve can be analyzed by using the equation

$$
M_{\text {mass }}(B, T)=w_{P F} \times\left\{M_{F e}^{-1} \times\left(N_{A} \mu_{B} \mu\right) \times\left[\frac{\operatorname{coth}(x)-1}{x}\right]\right\}+\left(1-w_{P F}\right) \times\left(\frac{\chi_{\text {dia }}}{\mu_{0}}\right) B_{\text {ext }}
$$

For the argument

$$
x=\mu_{B} \mu \frac{\left(B_{\text {ext }}+B_{\text {int }}\right)}{k_{B} T}
$$

Here $\mu$-magnetic moment in units of Bohr magneton, $M_{\mathrm{Fe}}$-the molar mass of iron, $w_{\mathrm{PF}}$-mass fraction of the paramagnetic species; physical constants adopt their usual meaning. The internal magnetic field $B_{\text {int }}=W \times M$ is expressed by the Weiss field constant $W$ and it causes the appearance of the remnant magnetization and the magnetic hysteresis. These equations need be solved by an iterative procedure.

The calculated magnetization curve for the sample under study is in a satisfactory agreement with the experimental data and the retrieved parameters are listed in Table 3. In this measurement the admixed

\begin{tabular}{|c|c|c|c|c|c|c|c|c|c|c|}
\hline \multirow[b]{2}{*}{ Sample classification } & \multicolumn{5}{|c|}{$T=150-250 \mathrm{~K}$} & \multicolumn{5}{|c|}{$T=2 \mathrm{~K}$} \\
\hline & Age & Sex & class & C & $\alpha / 10^{-3}$ & $w_{\mathrm{PF}} / 10^{-6}$ & $\underset{\times 10^{-3}}{\left(x_{\mathrm{dia}} / \mu_{0}\right)}$ & $\mu_{\mathrm{B}} \mu$ & $W / 10^{-3}$ & $M_{\mathrm{R}} / 10^{-3}$ \\
\hline la & 69 & $\mathrm{~F}$ & 1 & 0.11 & -8.9 & 190 & 0 & 4.32 & 0.47 & 0.24 \\
\hline $\mathrm{lb}$ & 52 & $\mathrm{M}$ & 1 & 0.27 & -8.1 & 106 & -8.74 & 6.03 & 0.41 & 0.52 \\
\hline Ila & 83 & $\mathrm{~F}$ & II & 3.33 & -10.2 & 72 & -9.38 & 7.51 & 1.87 & 3.24 \\
\hline $\mathrm{Ilb}$ & 66 & $M$ & II & 0.44 & -7.0 & 163 & -9.22 & 4.98 & 1.57 & 1.76 \\
\hline IIla & 53 & $M$ & III & 0.099 & 6.4 & 128 & -17.14 & 6.14 & 1.10 & 1.82 \\
\hline Illb & 73 & $M$ & III & 0.35 & 7.2 & 122 & -14.4 & 6.32 & 0.84 & 1.81 \\
\hline
\end{tabular}
paramagnetic signal is strong enough and masks the diamagnetic

asI units: Curie constant $C\left[\mathrm{~m}^{3} \mathrm{~kg}^{-1} \mathrm{~K}\right]$; temperature-independent term $\alpha$ and $X_{\text {dia }}\left[\mathrm{m}^{3} \mathrm{~kg}^{-1}\right]$; magnetic moment per particle $\mu_{\mathrm{B}} \mu\left[\mathrm{J} \mathrm{T}-1\right.$, Weiss-field constant $W\left[\mathrm{~J}^{-1} \mathrm{~T}^{2} \mathrm{~kg}\right]$; remnant magnetization $M_{\mathrm{R}}\left[\mathrm{J} \mathrm{T}^{-1} \mathrm{~kg}^{-1}\right]$

Table 3: Susceptibility and magnetization parameters for representative samples.
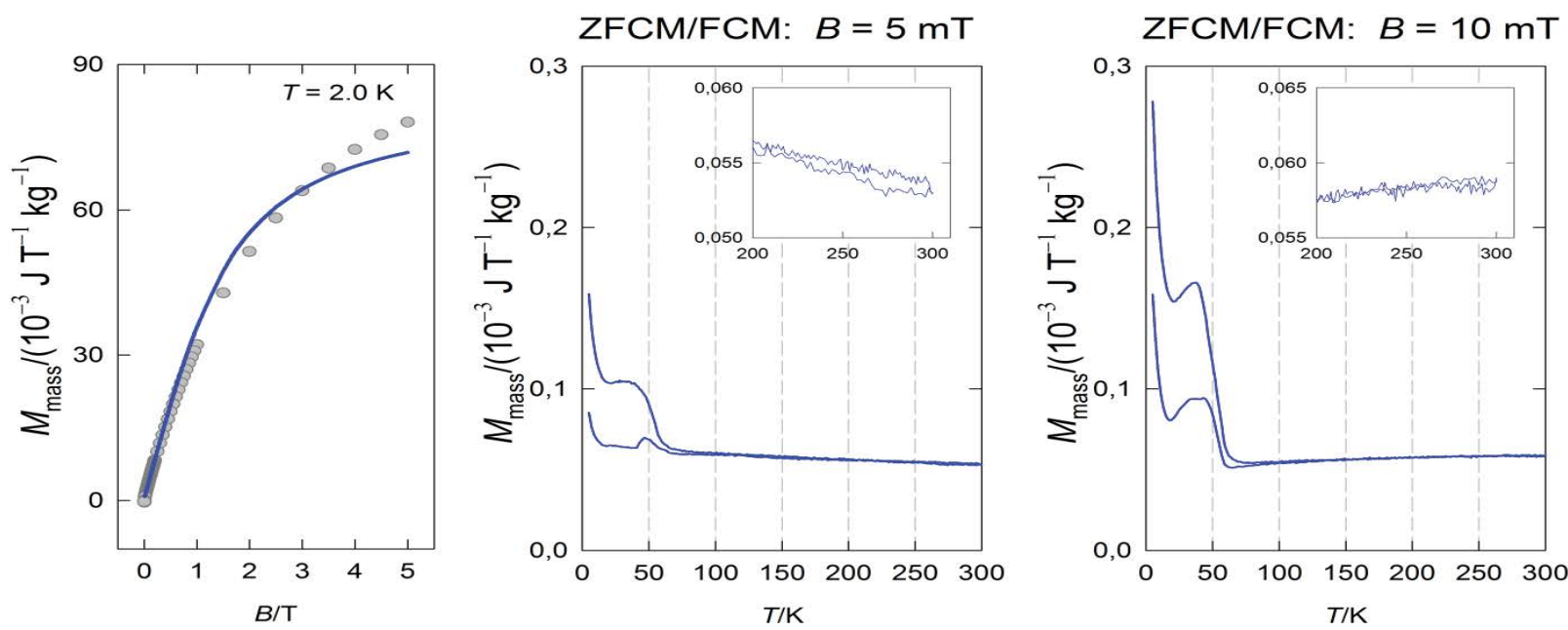

Figure 5: Left: field evolution of the mass magnetization for class I sample la; solid line-fitted. Centre and right: ZFCM/FCM experiments. 
Citation: Kopáni M, Hlinková J, Ehrlich H, Valigura D, Boča R (2017) Magnetic Properties of Iron Oxides in the Human Globus pallidus. J Bioanal Biomed 9: 080-090. doi:10.4172/1948-593X.1000158

background at $T=2.0 \mathrm{~K}$. There is some remnant magnetization $M_{\mathrm{R}}$, Weiss field $W$, and the retrieved magnetic moment is $\mu=4.3 \mu_{B}$.

The sample was heated up to the room temperature and then cooled to $2 \mathrm{~K}$ at the zero fields. Then small magnetic field was applied (5 $\mathrm{mT}$ and/or $10 \mathrm{mT}$ ) and the magnetization data was taken on the heating up to the room temperature in the settle mode (ZFCM experiment). The data was acquired during the cooling phase with the same applied field (FCM experiment). These records are also presented in Figure 5. The two curves merge approximately at $100 \mathrm{~K}$ which is the paramagnetic region. Notice an anomaly at $c a 40 \mathrm{~K}$ that is below the expected solidussolidus transition for the oxygen contaminated sample. With the doubled field the magnetization data is approximately doubled that confirms a reproducibility of these measurements.

The hysteresis loops are visualized in Figure 6. With increasing temperature the paramagnetic signal decays and diamagnetic background starts to dominate. Consequently the profile of the magnetization curve alters from the S-shape to the Z-one. Above $T$ $>100 \mathrm{~K}$ the hysteresis loop stays almost unchanged.

\section{Magnetization data for class III}

For the class III compound (that is paramagnetic at $B=0.1 \mathrm{~T}$ in the whole temperature region) the situation is different as shown by magnetization measurements in Figure 7. The virgin magnetization curve differs from that measured after several exposures to a strong magnetic field when the magnetic nanoparticles are subjected to an ordering.
Also the ZFCM/FCM experiments were done for this sample. It is registered that the devitrification point (when the FCM/ZFCM curves coincide) is not below $300 \mathrm{~K}$ which means that the Curie temperature $T_{\mathrm{C}}$ lies above $300 \mathrm{~K}$. A feature around $50 \mathrm{~K}$ is characteristic for the presence of magnetite but this could be due to the phase transition for solid oxygen present in the sample.

The search for the presence of magnetic hysteresis of the class III types was positive, and the recorded representative curves are displayed in Figure 8. The hysteresis loop survives until the room temperature. Again one can register a switch of the $\mathrm{S}$ - to the $\mathrm{Z}$-shaped magnetization curves on the heating. It is registered that the hysteresis loops possess a complex structure, especially at higher temperature, that indicates a multicomponent character of the sample. They, however, keep a perfect symmetry on field reversal. Thus, individual features are not artifacts of the particular measurement (hardware limitations, noise).

The measurements for $T=300 \mathrm{~K}$ have been repeated and identical hysteresis loop was recorded. In these records the SQUID response passes through zero when the system fails in fitting to the ideal dipole function. Those artifact points with the regression fit coefficient $<0.8$ have to be removed. After subtraction of an overall linear diamagnetic signal $\left(M_{\text {dia }}=-17.2 \times 10^{-3} \mathrm{~J} \mathrm{~T}^{-1} \mathrm{~kg}^{-1}\right)$ the coercive field becomes $9 \mathrm{mT}$ at the room temperature. In an analogous treatment $B_{c}=10,12$ and $13 \mathrm{mT}$ for $T=150,100$, and $70 \mathrm{~K}$, respectively.

\section{Magnetization data for class II}

Magnetization data for the class II sample is presented in Figure 9.

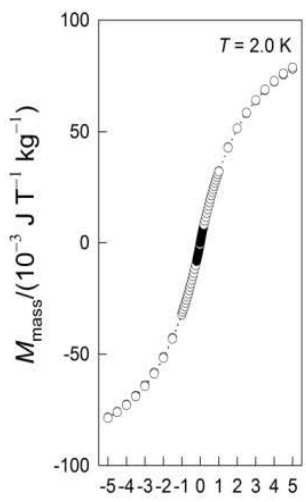

$B / T$

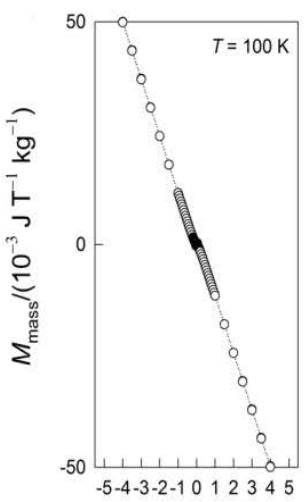

B/T

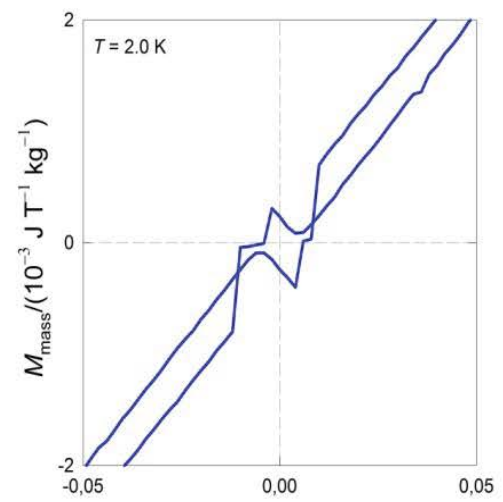

B/T

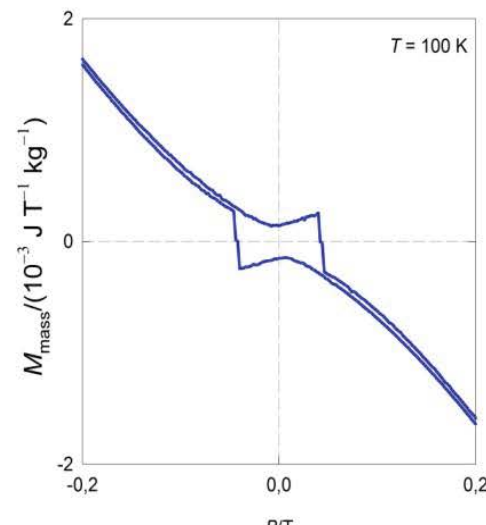

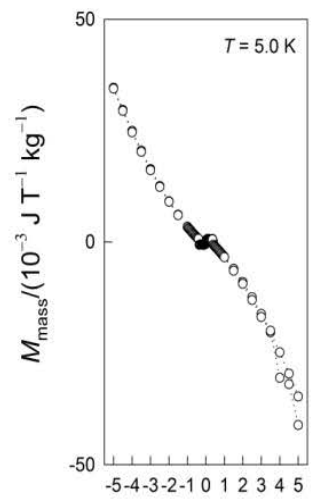

$B / T$

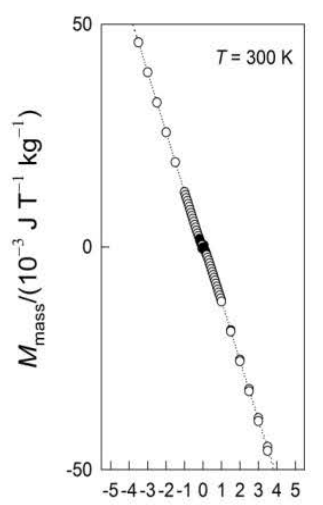

$B / T$
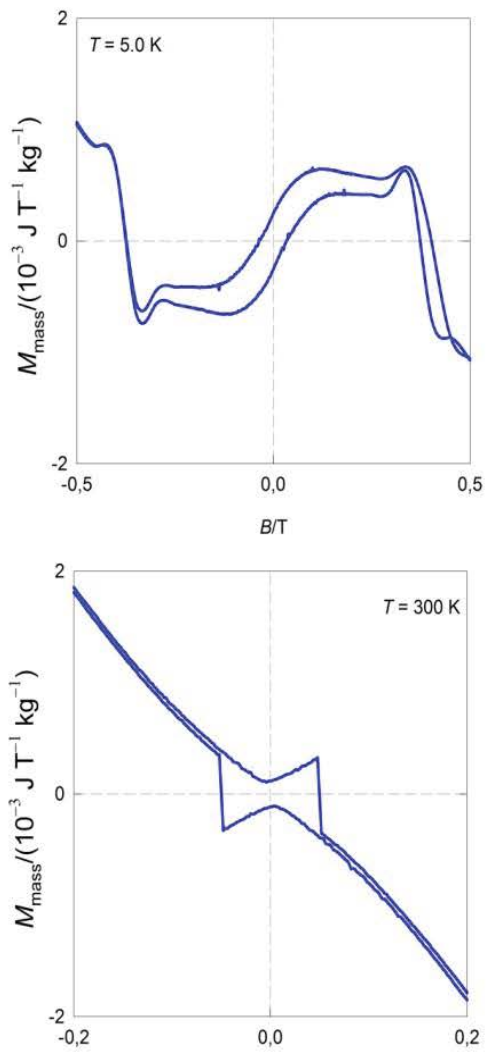

B/T

Figure 6: Hysteresis loops at various temperatures for class I sample la. Diamagnetic signal not subtracted. 

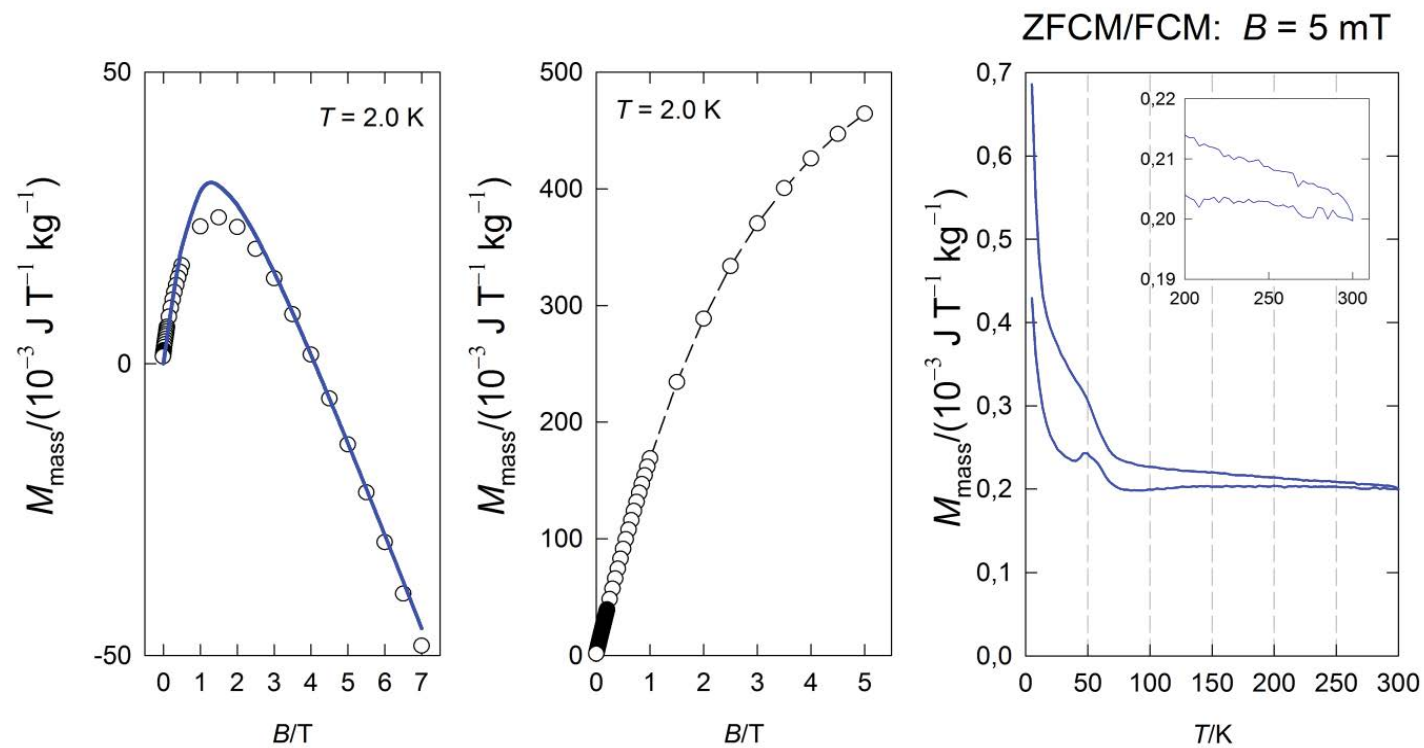

Figure 7: Left: field evolution of the mass magnetization for class III (virgin) sample IIla; solid line-fitted; Centre: field treated sample; Right: ZFCM/FCM experiments.

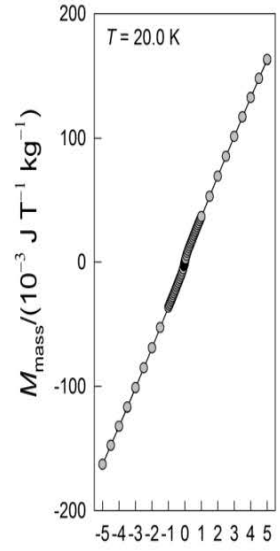

$B / T$

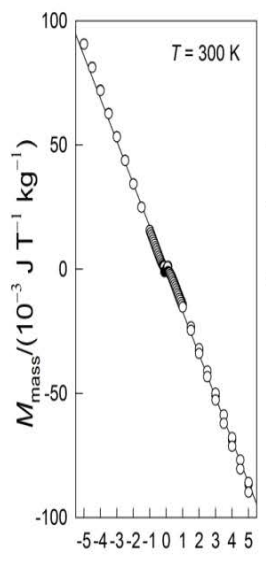

$B / T$

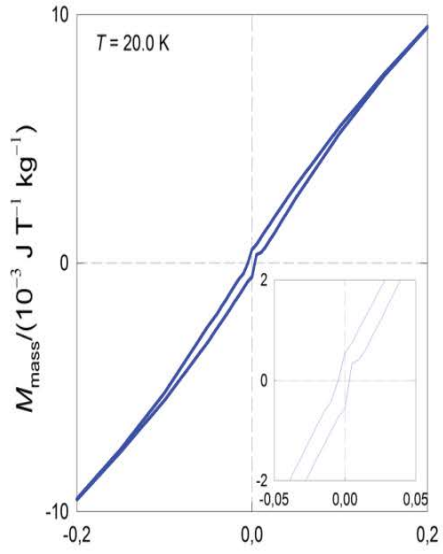

$B / T$

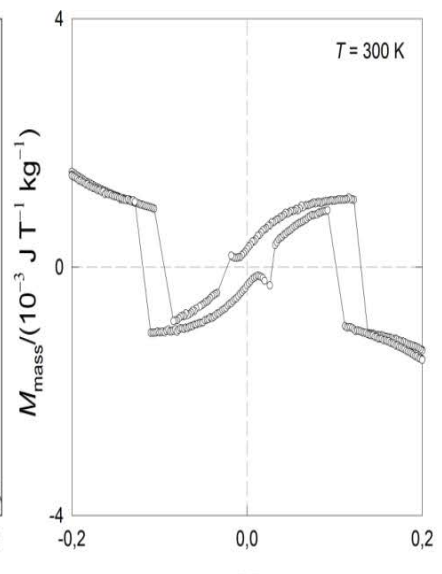

$B / T$

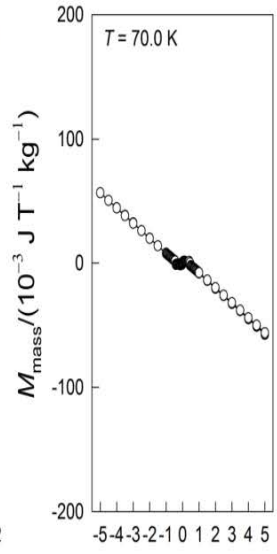

$B / T$

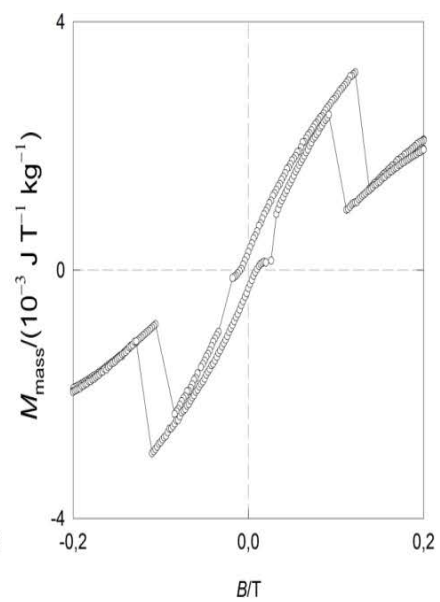

Figure 8: Hysteresis curves for the class III (sample IIla); bottom-right-after subtraction of the diamagnetic signal and removal of artifact points. 
The mass magnetization passes through a maximum at $2 \mathrm{~K}$ and then it decays in accordance with the prevailing diamagnetic response at the higher fields. The ZFCM/FCM intercept exceeds $300 \mathrm{~K}$ so that there is indication that the magnetic hysteresis will survive to the room temperature.

Indeed, the sample belonging to class II exhibits the magnetic hysteresis as shown in Figure 10. The complexity manifests itself not only on the course of the magnetic susceptibility (and/or the product function $\chi T$ ), but also in the profile of the magnetization curves. As evident, the Z-shaped high-field part possesses an S-shaped low-field insert; just this insert escapes on the heating. The coercivity again depends on temperature: in the series of $T=5,10,20,50,100,200$ and $300 \mathrm{~K}$ the coercive field varies as $B=73,24,17,9,22$ (12), 20 (10) and 18 (8) $\mathrm{mT}$ where values in parentheses refer to the loop after subtracting the diamagnetic background.

Temperature evolution of the remnant magnetization $M_{\mathrm{r}}$ is given in Figure 11. It is seen that this property decreases with increasing temperature, the fact that matches expectation. Unlike the expectation, the $M_{\mathrm{r}}$ values are higher for the class II sample at low temperature.

Returning to the Table 3, clear difference among the three classes is represented by the Weiss field constant at $T=2.0 \mathrm{~K}: W<0.5$ for class-I, $W \sim 1.0$ for class-II, and $W>1.5$ for class III (in the given units). Just this parameter characterizes the long-range ordering. The temperatureindependent susceptibility term is $\alpha<0$ for class I and II, whereas $\alpha>0$ holds true for class III samples.

\section{Discussion}

Iron deposits are found in places with high metabolic activity around glial cells and are physiologically accumulated depending on age $[23,24]$. Iron is the metal that can form ferrimagnetic compounds with oxygen and/or sulfur. However, sulfide minerals have only been reported accompanying bacterial activity [15]. Our findings of iron depositions near glial cells agree with results of other studies [25-27].

Magnetic properties of iron compounds depend greatly on the ligand-based environment. Ferritin as an iron storage globule displays a superparamagnetic behavior and in its inorganic core it contains about 4500 atoms of $\mathrm{Fe}$ (III) [28]. Ferromagnetic deposits of iron oxides in the form of nanocrystals of magnetite in the human brain were observed for the first time by Kirschvink et al. [19].

The complexity of the samples under study can be enumerated as follows. Each sample is unique and there is no chance for its reconstruction or synthesis and thus only small amounts should be used for any destructive investigative methods. The mass of the sample depends upon the degree of lyophilization and the sample behaves unlike to inorganic salts that can be grained to a fine powder and eventually fix by some additives or as pellets. The mass loss caused lyophilization leads to a higher concentration of iron deposits in the sample under investigation and a reduction of the diamagnetic background given by water and tissues.

Each sample contents magnetic particles of different sizes, compositions and counts. The iron-oxide minerals that are antiferromagnetic at bulk possess uncompensated spins at the surface the contribution of which increases with the decreasing size. Thus the overall paramagnetic response can originate in the ferritin, magnetite $\left(\mathrm{Fe}_{3} \mathrm{O}_{4}\right)$, maghemite $\left(\gamma\right.$ - $\left.\mathrm{Fe}_{2} \mathrm{O}_{3}\right)$ as well as nanoparticles of hematite $\left(\alpha-\mathrm{Fe}_{2} \mathrm{O}_{3}\right), \mathrm{FeO}, \mathrm{FeOOH}$ and other minerals along with some other compounds of transition metals (like $\mathrm{Cu}(\mathrm{II})$ ) and dioxygen itself. The accumulation of these species could be different in the different part of the brain and depends upon disease and age.

Identification of the hematite nano/microparticles in the human brain by electron microscopy is rather surprising since just this mineral is missing among deposits in a huge group of animals. However, the hematite, weakly-magnetic in bulk at the room temperature, is the thermodynamically most stable iron-oxide mineral and this could appear as the end-product on the human aging. Particles of hematite smaller than $8 \mathrm{~nm}$ display superparamagnetic behavior at the room temperature [29].

Samples of human Globus pallidus from the view of magnetic susceptibility may be classified into three groups-dominating diamagnetism with some paramagnetic impurities (class I),
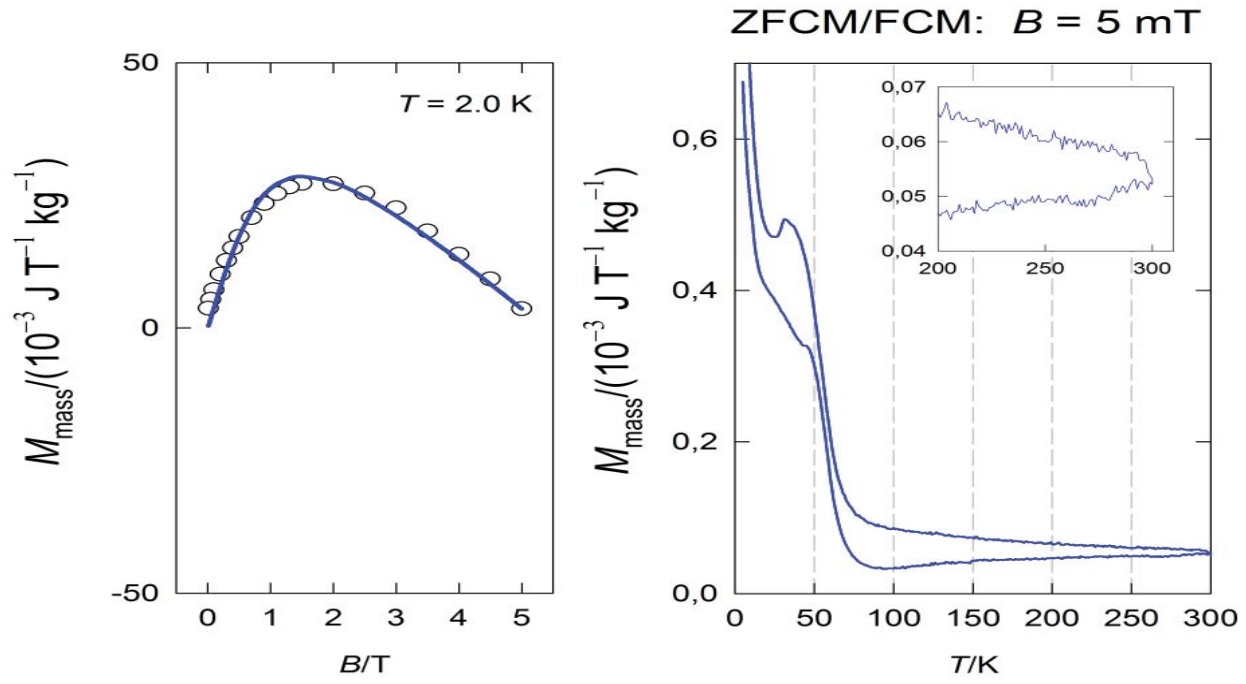

Figure 9: Left: field evolution of the mass magnetization for class II (virgin) sample Ila; solid line-fitted; right: ZFCM/FCM experiments. 


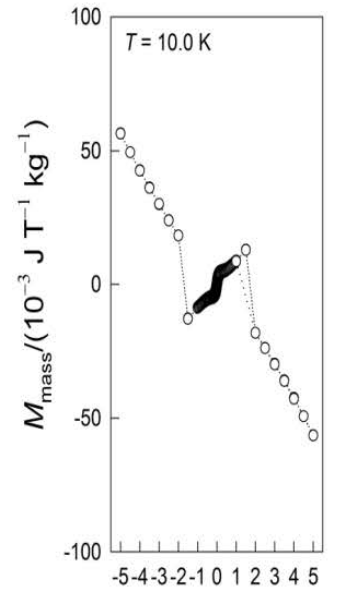

$B / T$

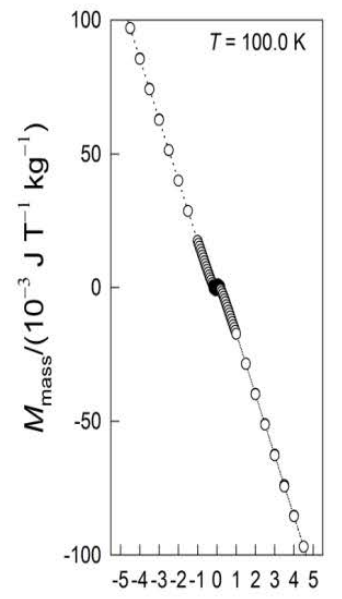

$B / T$
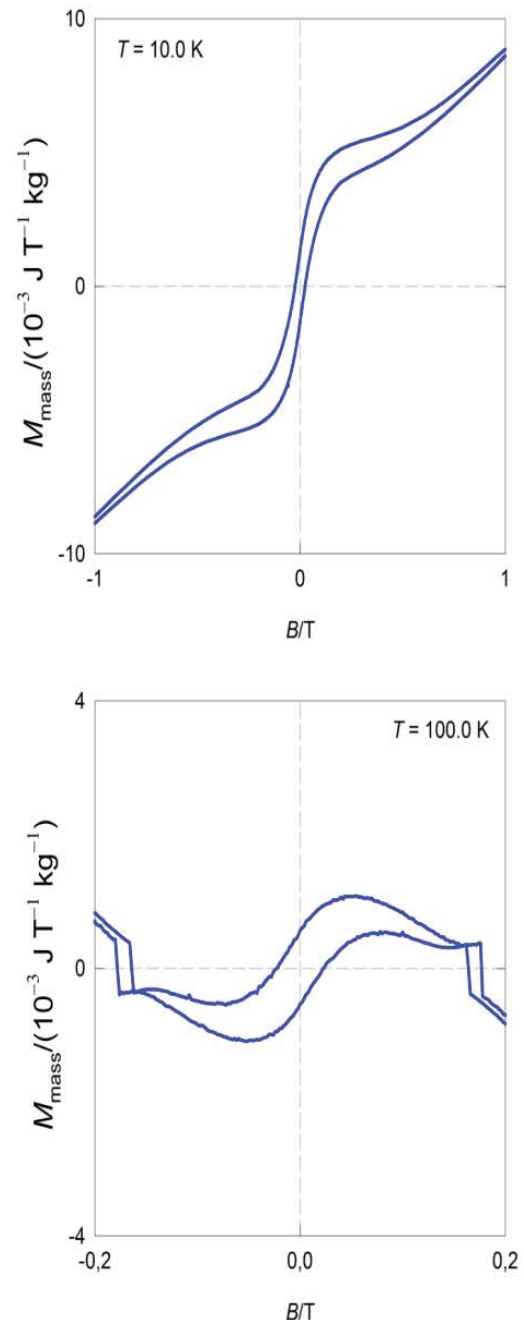

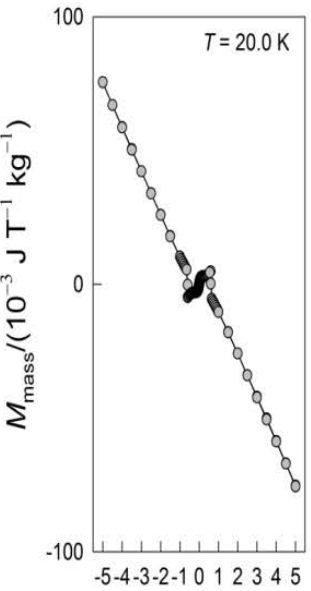

$B / T$

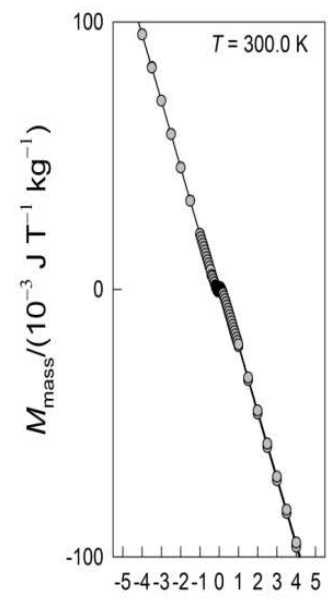

$B / T$
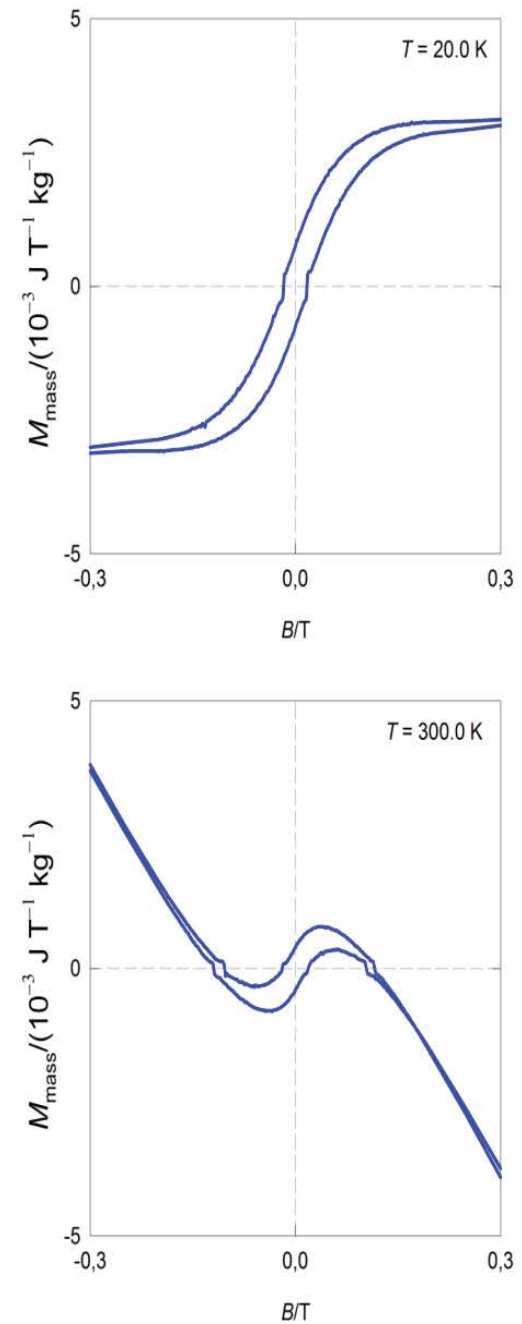

Figure 10: Hysteresis curves for the class II (sample Ila); diamagnetic signal not subtracted.
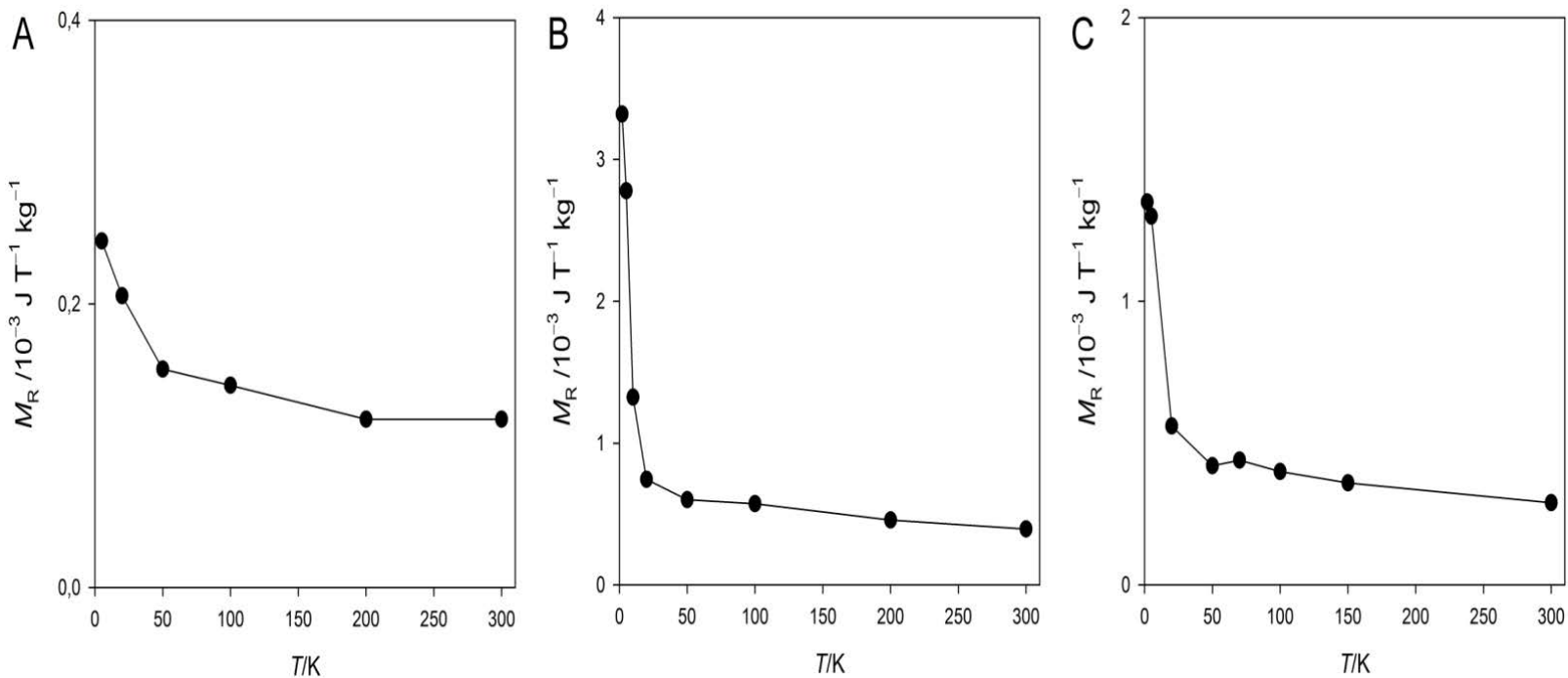

Figure 11: Temperature dependence of the remnant magnetization. A) Class I (sample la) (B) Class II (sample Ila) (C) Class III (sample IIla) 
paramagnetic and diamagnetic with much stronger paramagnetic and/ or ferromagnetic components (class III), and an "intermediate" group (class II). A classification according to the temperature evolution of the magnetic susceptibility or the product function $\chi T$ is somewhat arbitrary, since this can be influenced by the applied field and the sample treatment (exposure to high magnetic fields).

In all classes the ZFCM/FCM experiments confirm a rather high devitrification temperature: ca $100 \mathrm{~K}$ for class $\mathrm{I}$, and $T_{\mathrm{C}}>300 \mathrm{~K}$ for class II and class III samples. Nevertheless, the magnetic hysteresis survives for all three classes until the room temperature with different remnant magnetization (lowest for class I, highest for class II). Temperature dependence of the remnant magnetization for class II and class III shows a similar course. This data does not correspond to the presence of $\mathrm{O}_{2}, \mathrm{Cu}(\mathrm{II}), \mathrm{Cr}(\mathrm{III}), \mathrm{Fe}(\mathrm{III}) / \mathrm{Fe}(\mathrm{II})$, ferritin or other paramagnetic species. Moreover, FCM/ZFCM measurements do not match the presence of ferritin because of absence the fingerprint feature (a maximum at the ZFCM curve) at $c a 10 \mathrm{~K}$ [30]. In addition, FCM/ZFCM measurements show features at around $50 \mathrm{~K}$ that are characteristic for the presence of magnetite [31]. The Verwey (charge ordering) phase transition at 120 $\mathrm{K}$, characteristic for the magnetite, is seen neither on the susceptibility curve nor on the ZFCM curve; this supports the presence of maghemite.

To this end, the remnant magnetization, coercive field and ZFCM/ FCM profiles indicate a presence of magnetite or maghemite. Notice, magnetite can be formed from ferrihydrite as a precursor [32]. However, Kobayashi et al. [15] reported that the distribution of ferritin is not correlated to the distribution of magnetite in the human brain. From these results it can be concluded that magnetite is not formed spontaneously from ferritin, but through a biochemically controlled processes.

Hysteresis curves of the class III sample reveal a variation of the coercivity with temperature: On temperature elevation $T=2,5,20,50$, and $70 \mathrm{~K}$ the coercive field varies in a non-systematic way as $B=7,11,4$, 5 , and $17 \mathrm{mT}$. Between $T=100-300 \mathrm{~K}$, however, the shape of the hysteresis loop becomes very complex and the coercive field is problematic to read off. The first cross with the zero magnetization occurs at 50,41 , and $28 \mathrm{mT}$ for $T=100,150$, and $300 \mathrm{~K}$. Two other crosses lie at 94 and 124 $\mathrm{mT}$ for $T=300 \mathrm{~K}$. Coercivity between $20-30 \mathrm{mT}$ has been assigned to magnetite and/or maghemite $[31,33]$.

The complexity of the hysteresis loops (especially for class III sample) may be caused by a multicomponent composition of the samples containing deposits of several magnetic and non-magnetic iron oxides $\left(\alpha-\mathrm{Fe}_{2} \mathrm{O}_{3}, \gamma-\mathrm{Fe}_{2} \mathrm{O}_{3}, \mathrm{Fe}_{3} \mathrm{O}_{4}\right)$ of different size, shape, and count [34].

Variations of the magnetic properties of brain tissue can have several different biophysical origins-ferritin accumulation [35], the presence of mineral deposits [16,22], various structure of ferritin iron core during ageing [36-39] and interaction between iron and the surrounding environment [40]. The organic components of the cell-lipids, proteins and polysaccharides can influence the biomineralization process by acting as a general surface for accumulation. Two models have been proposed to explain the interactions between iron(III) and (poly) saccharides. Results of this interaction are various iron oxyhydroxides such as hematite, ferrihydrite, magnetite, goethite, akaganéite or iron metal.

\section{Conclusion}

Deposits of iron oxides in the Globus pallidus of the human brain are visible under optical microscope as objects of regular and or/irregular shape and giving sharp diffraction patterns in the transmission mode of electron microscopy confirming their crystallinity. The SQUID magnetometry shows that the magnetization curves deviates form an ideal Langevin function due to the dominating diamagnetism of organic tissue. Owing to different portion of magnetic particles (nano/ microcrystals of $\mathrm{Fe}_{3} \mathrm{O}_{4}$ and/or $\gamma-\mathrm{Fe}_{2} \mathrm{O}_{3}$ ) the hysteresis curves detected even at the room temperature display a complex course. Based on magnetic susceptibility, the samples can be classified into three groups: Class I with dominating diamagnetism, class III with prevailing paramagnetism, and the intermediate class II. This classification is supported also by the Weiss field parameter that characterizes the average long-range ordering.

\section{Acknowledgments}

This work was supported by the Slovak grant agency VEGA-1/0919/17 and APVV-14-0078.

\section{References}

1. Langkammer C, Krebs N, Goessler W, Scheurer E, Ebner F, et al. (2010) Quantitative MR imaging of brain iron: a postmortem validation study. Radiology 257: 455-462.

2. Koeppen AH (1995) The history of iron in the brain. J Neurol Sci 134: 1-9.

3. Mikhaylova A, Davidson M, Toastmann H, Channell JET, Guyodo Y, et al (2005) Detection, identification and mapping of iron anomalies in brain tissue using X-ray absorption spectroscopy. J R Soc Interface 2: 33-37.

4. Jo DG, Lee JY, Hong YM, Song SM, Mook-Jung I, et al. (2004) Induction of pro-apoptotic calsenilin/DREAM/KChIP3 in Alzheimer's disease and cultured neurons after amyloid-beta exposure. J Neurochem 88: 604-611.

5. Friedland RP, Luxenberg JS, Koss E (1990) A quantitative study of intracrania calcification in dementia of the Alzheimer type. Int Psychogeriatr 2: 36-43.

6. Vermersch P, Leys D, Pruvo JP, Clarisse J, Petit H (1992) Parkinson's disease and basal ganglia calcifications: prevalence and clinico-radiological correlations. Clin Neurol Neurosurg 94: 213-217

7. Zecca L, Youdim MBH, Riederer P, Connor JR, Crichton RR (2004) Iron, brain ageing and neurodegenerative disorders. Nat Rev Neurosci 5: 863-873.

8. Stankiewicz JM, Neema M, Ceccarelli A (2014) Iron and multiple sclerosis. Neurobiol Aging 35: S51-S58.

9. Ercal N, Gurer-Orhan H, Aykin-Burns N (2001) Toxic metals and oxidative stress part I: mechanisms involved in metal-induced oxidative damage. Curr Top Med Chem 1: 529-539.

10. Arruda LF, Arruda SF, Campos NA, de Valencia FF, Siqueira EMDA (2013) Dietary iron concentration may influence aging process by altering oxidative stress in tissues of adult rats. PLoS One 8: e61058.

11. Piñero DJ, Connor JR (2000) Iron in the Brain: An Important Contributor in Normal and Diseased States. Neuroscience 6: 435-453.

12. Bartzokis G, Aravagiri M, Oldendorf WH, Mintz J, Marder SR (1993) Field dependent transverse relaxation rate increase may be a specific measure of tissue iron stores. Magn Reson Med 29: 459-464.

13. Bulte JW, Miller GF, Vymazal J, Brooks RA, Frank JA (1997) Hepatic hemosiderosis in non-human primates: quantification of liver iron using different field strengths. Magn Reson Med 37: 530-536

14. Galvez N, Fernandez B, Sanchez P, Cuesta R, Ceolin M, et al. (2008) Comparative structural and chemical studies of ferritin cores with gradual removal of their iron contents. J Am Chem Soc 130: 8062-8068.

15. Kobayashi A, Yamamoto N, Kirschvink J (1997) Studies of Inorganic Crystals in Biological Tissue: Magnetite in Human Tumor. J Jpn Soc Powder Powder Met 44: 294-300

16. Hautot D, Pankhurst QA, Khan N, Dobson J (2003) Preliminary evaluation of nanoscale biogenic magnetite in Alzheimer's disease brain tissue. Proc R Soc B-Biol Sci 270: S62-S64.

17. Dubiel SM, Zablotna-Rypien B, Mackey JB (1999) Magnetic properties of human liver and brain ferritin. Eur Biophys J 28: 263-267.

18. Allen PD, St Pierre TG, Chua-anusorn W, Strom V, Rao KV (2000) Low- 
Citation: Kopáni M, Hlinková J, Ehrlich H, Valigura D, Boča R (2017) Magnetic Properties of Iron Oxides in the Human Globus pallidus. J Bioanal Biomed 9: 080-090. doi:10.4172/1948-593X.1000158

frequency low-field magnetic susceptibility of ferritin and hemosiderin. Biochim Biophys Acta 1500: 186-196.

19. Kirschvink JL, Kobayashi-Kirschvink A, Woodford BJ (1992) Magnetite biomineralization in the human brain. Proc Natl Acad Sci U S A 89: 7683-7687.

20. Kopani M, Kopaniova A, Caplovicova M, Maruscakova L, Sisovsky V, et al.(2014) Iron and its relation to glycoconjugates in human globus pallidus. Bratisl Med J 115: 362-366.

21. Kopani M, Miglierini M, Lancok A, Dekan J, Caplovicova M, et al. (2015) Iron oxides in human spleen. Biometals 28: 913-928.

22. Langkammer C, Schweser F, Krebs N, Deistung A, Goessler W, et al. (2012) Quantitative susceptibility mapping (QSM) as a means to measure brain iron? A post mortem validation study. Neuroimage 62: 1593-1599.

23. Connor JR, Menzies SL, Burdo JR, Boyer PJ (2001) Iron and iron management proteins in neurobiology. Pediatr Neurol 25: 118-129.

24. Hallgren $B$, Sourander $P(1958)$ The effect of age on the non-haemin iron in the human brain. J Neurochem 3: 41-51.

25. Casanova MF, Araque JM (2003) Mineralization of the basal ganglia: implications for neuropsychiatry, pathology and neuroimaging. Psychiatry Res 121: 59-87.

26. Kobayashi S, Yamadori I, Miki H, Ohmori M (1987) Idiopathic nonarteriosclerotic cerebral calcification (Fahr's disease): an electron microscopic study. Acta Neuropathol 73: 62-66.

27. Morris CM, Candy JM, Oakley AE, Bloxham CA, Edwardson JA (1992) Histochemical distribution of non-haem iron in the human brain. Acta Anat (Basel) 144: 235-257.

28. Cornell RM, Schwertmann U (2003) The Iron Oxides-Structure, Properties, Reactions, Occurences and Uses ( $2^{\text {nd }}$ edn.) Wiley-VCH, Weinheim, Cambridge, UK.

29. Makhlouf SA, Parker FT, Berkowitz AE (1997) Magnetic hysteresis anomalies in ferritin. Phys Rev B 55: R14717-R14720.

30. Brem F, Hirt AM, Simon C, Wieser HG, Dobson J (2005) Characterization of iron compounds in tumour tissue from temporal lobe epilepsy patients using low temperature magnetic methods. Biometals 18: 191-197.

31. Mann S (1993) Molecular tectonics in biomineralization and biomimetic materials chemistry. Nature 365: 499-505.

32. Brem F, Hirt AM, Winklhofer M, Frei K, Yonekawa Y, et al. (2006) Magnetic iron compounds in the human brain: a comparison of tumour and hippocampal tissue. J R Soc Interface 3: 833-841.

33. Sant'Ovaia H, Marques G, Santos A, Gomes C, Rocha A (2015) Magnetic susceptibility and isothermal remanent magnetization in human tissues: a study case. Bio Metals 28: 951-958.

34. Gutiérrez L, Quintana C, Patiño C, Bueno J, Coppin H, et al. (2009) Iron speciation study in Hfe knockout mice tissues: magnetic and ultrastructura characterisation. Biochim Biophys Acta 1792: 541-547.

35. Connor JR, Snyder BS, Arosio P, Loeffler DA, LeWitt P (1995) A quantitative analysis of isoferritins in select regions of aged, parkinsonian and Alzheimer Disease brains. J Neurochem 65: 717-724.

36. Zecca L, Gallorini M, Schünemann V, Trautwein AX, Gerlach M, et al. (2001) Iron, neuromelanin and ferritin in substantia nigra of normal subjects at different ages. Consequences for iron storage and neurodegenerative processes. J Neurochem 76: 1766-1773.

37. Kim BJ, Lee HI, Cho SB, Yoon S, Suh BJ, et al. (2005) Magnetic properties of artificially synthesized ferritins. J Appl Phys 97: $10 \mathrm{M} 524$.

38. Lee E, Kim DH, Hwang J, Lee K, Yoon S, et al. (2013) Size-dependent structural evolution of the biomineralized iron-core nanoparticles in ferritins. Appl Phys Lett 102: 133703.

39. Yang CY, Bryan AM, Theil EC, Sayers DE, Bowen LH (1986) Structural variations in soluble iron complexes of models for ferritin: an x-ray absorption and Mössbauer spectroscopy comparison of horse spleen ferritin to Blutal (ironchondroitin sulfate) and Imferon (iron-dextran). J Inorg Biochem 28: 393-405.

40. Sipos P, Berkesi O, Tombácz E, St Pierre TG, Webb J (2003) Formation of spherical iron(III) oxyhydroxide nanoparticles sterically stabilized by chitosan in aqueous solutions. J Inorg Biochem 95: 55-63. 